
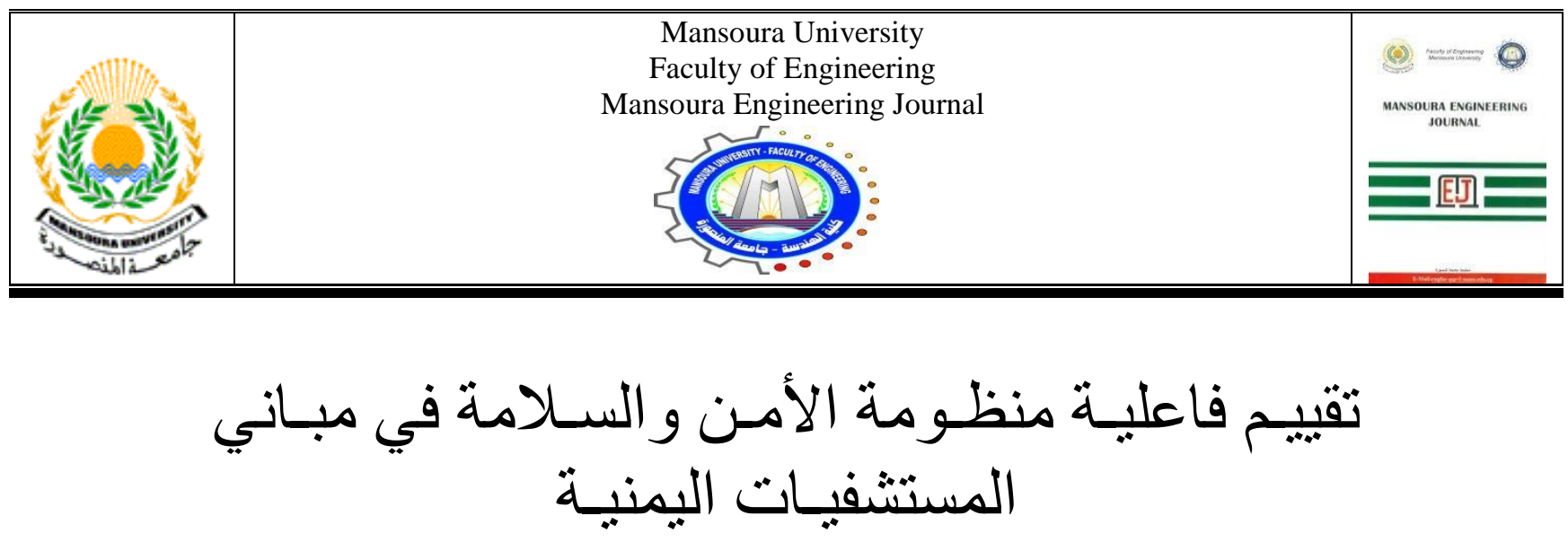

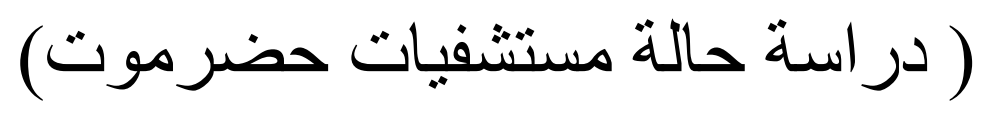

\title{
Assessing the Efficiency of Security and Safety System in Yemen's Hospitals (Case Study of Hospitals in Hadramout)
}

\author{
Wafa Abdullah Abdulrab Balala and Khaled Mohamed Ahmed El-lithy*
}

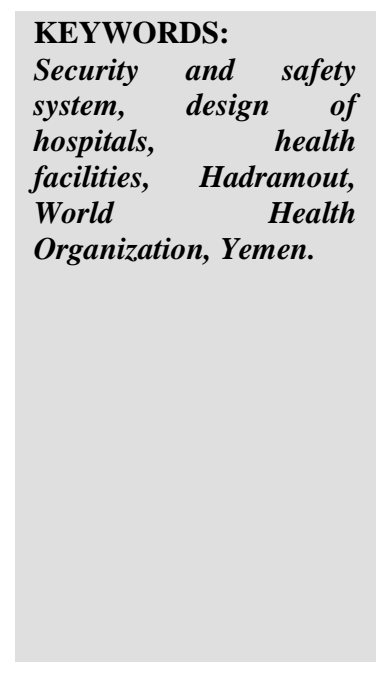

\begin{abstract}
This paper discusses the importance of having appropriate methodology to evaluate security and safety system that provide a safe environment for individuals and users in health care facilities. Analyses show a defect in the design and function, which represent the problem of this study.

This paper aims to develop a global methodology for evaluate performance of the system for selected sample of hospitals in Hadramout. Series analyzes was made in a paper earlier[8] determined the most important system criteria that should be provided to achieve the optimal performance of the system, which helps to formulating a appropriate system elements to requirements of Yemen environment depending on safety system approved by the World and Pan American Health Organizations.

This paper analyzes functional design of hospitals to determine the defected, protected and expected risks zones. In addition, to determine the relative weights (local scale) depend on analyzing results of questionnaires opinion addressed to a selected sample of users and work crews in selected hospitals in Hadramout. In order to evaluate performance of security and safety system to these hospitals. In addition, be generalized in Yemen hospitals a line with the nature of the local environment of the study area.
\end{abstract}

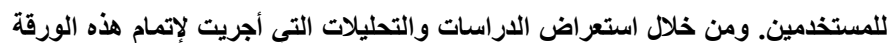

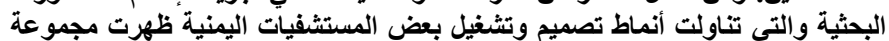

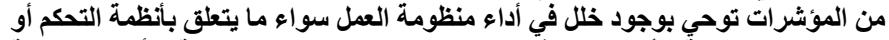

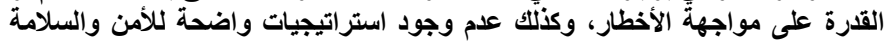

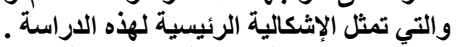

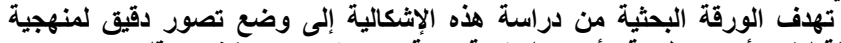

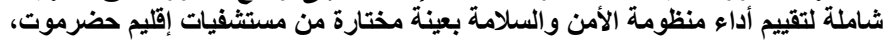

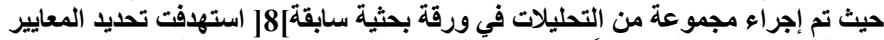

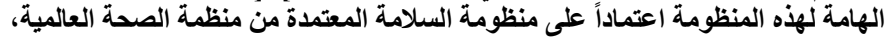
والتي تعتمد عليها الورقة الحالية في صياغة منهجية تقييم المنظومة المئمة الملائمة للبيئة

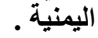

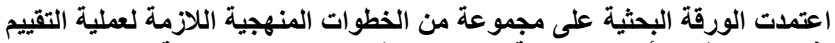

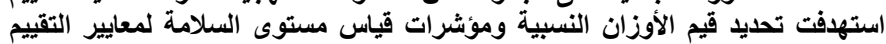

الهلخص العربي:-تناقش الورقة البحثية أهمية وجود منهجية واضحة يمكن من خلالها تقييم أداء منظومة الأمن والسلامة في المستثفيات بما يكفل توفير بيئة آمنة 2016

Received: 18 November 2015 - revised: 9 May, 2016 - accepted: 10 May,

Wafa Abdullah Abdulrab Balala, Ph.D. Student (May 2010-2016), Department of Architectural Engineering, Faculty of Engineering, Assiut University (email: waflab006@yahoo.com)

Corresponding Author: Khaled Mohamed Ahmed El-lithy, Assistant Professor at Department of Architectural Engineering, Faculty of Engineering, Assiut University. (email: khaled.elethi@eng.aun.edu.eg khaled03@yahoo.com) 
• الهذف الأول: صياغة معايير ومكونات عناصر منظومة الأمن و السلامة

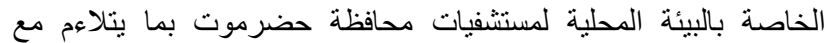

متطلبات منطقة الدر اسة.

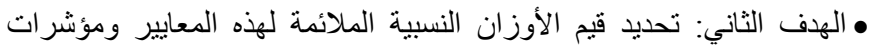

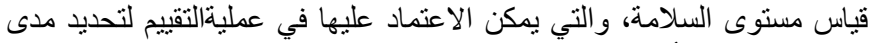
تحقق مستويات الأمان في عينات الدر اسة التي يتم تقييمها.

3-1

تعتمد الورقة البحثية على المنهج التحليلي لتقييم فاعلية منظومة الأمن

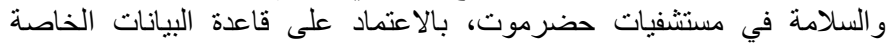

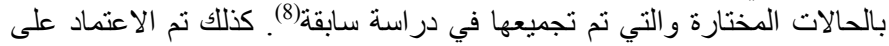

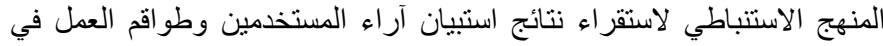

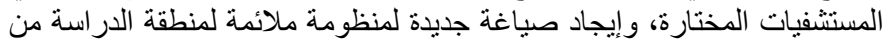

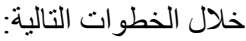

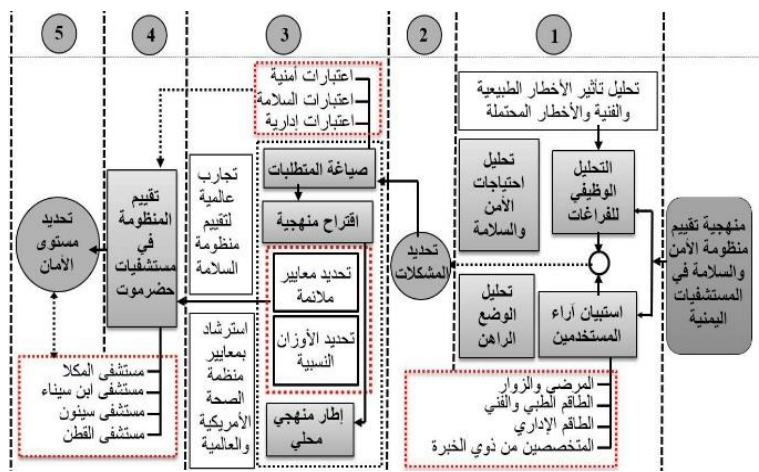

شكل (1): خطو ات منهجية تقييم منظومة الأمن و السلامة في مستشفيات حضرموت

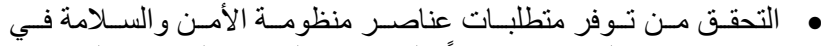

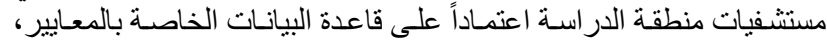
وتحليل نتائج استبيان الآراء.

• تحديد مواطن القصور الناتجة عن عدم تحقق معايير الأمن والسلامة.

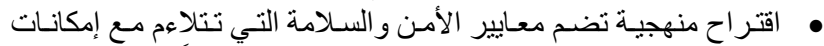

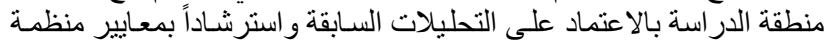

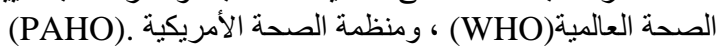

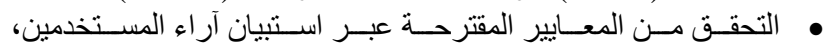

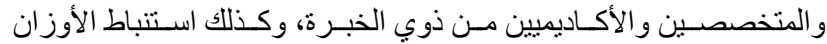
النسبية لها بما يتناسب مع طبيعة البيئة اليمنية.

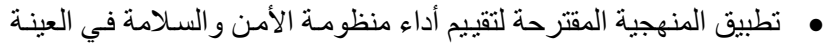

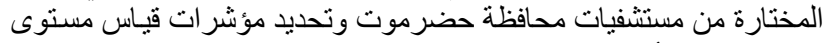

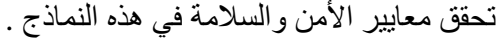

\section{II}

تهدف هذه المنظومة إلى رفع قدرة المستشفى للاستعداد للخطر وحماية

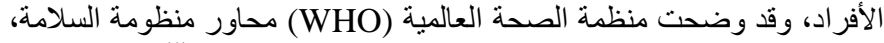

والتي ترمز إلى الاستر اتيجية المتبعة لتوفير السلامة بالمستشفيات العادة)، وهي:

$$
\text { 1-2 المحور الأول: حماية الأفراد }
$$

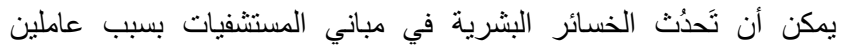

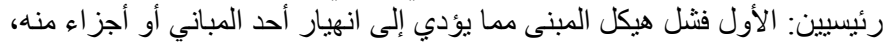

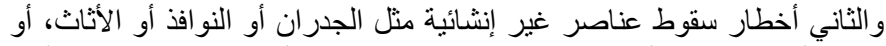

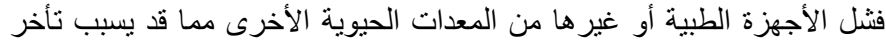

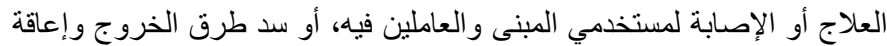

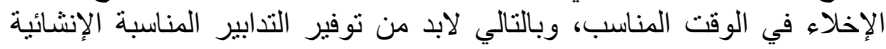
وغير الإنشائية لتقليل احتمال انهيار المباني أو سقوط مكوناتئه أو تعطلاها عن
المختلفة، من خلال تحليل نتائج استبيانات الرأي الموجهة إلى عينة مختارة من فئماء

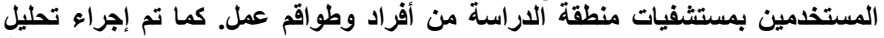
وظيفي لهذه المستثفيات بهاف إبراز مناطق الخلل وتحديد مناطق الحماية المطلوبة الحية ومناطق الأخطار المتوقعة.

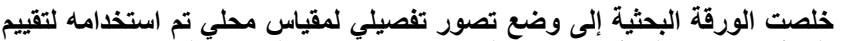

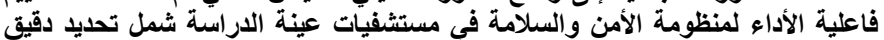

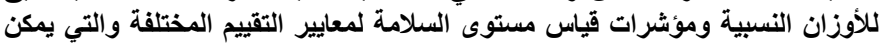
تعميمها كمنهجية للتقييم في المستشفيات اليمنية بما يتواكب مع طبيعة البيئة المحلية

\section{I I المقدمة}

هـ ـ عد منظومة الأمن والسلامة أهم المتطلبات اللازم توفرها في

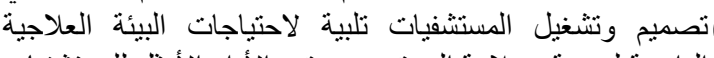

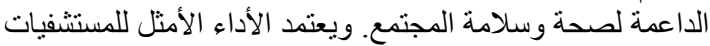

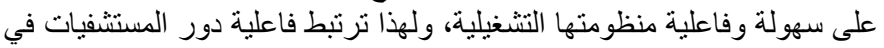

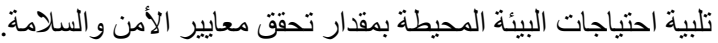

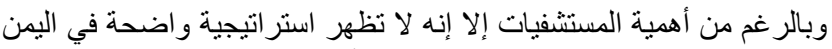

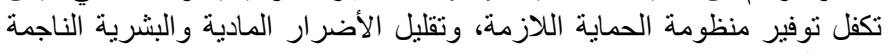

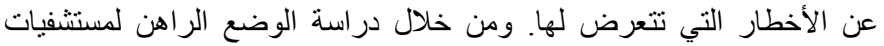

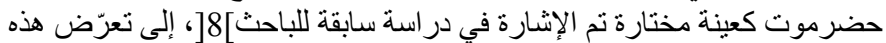

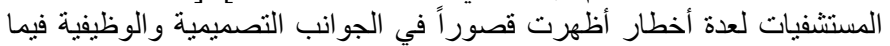

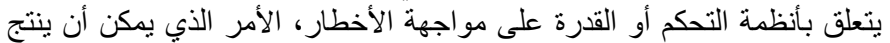

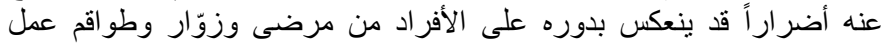
مختلفة .

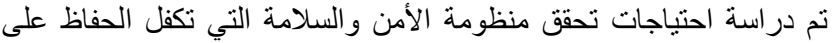

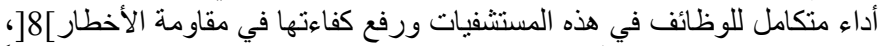
وتم من خلالها صباغة أهم معايير المنظومة الملائمة للبيئة المحلية استرشاداً

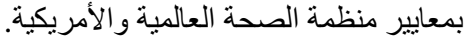
وتحاول هذه الورقة البحثية وضع تصنية الاهور دقية دقيق لخطوات منهجية لتقييم فاعلية

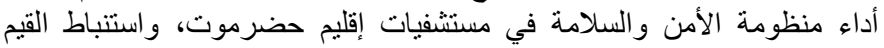

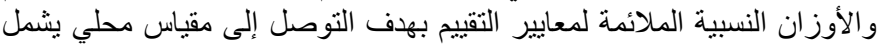

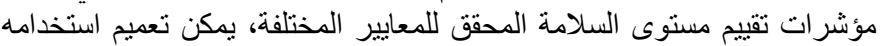
في تقييم أداء منظومة الأمن و السلامة في المستشفيات اليمنية.

1-1 الإثكالية البحثية

تتضح ملامح الإشكالية البحثية في قصور الأداء العام بمستشفيات إقليم

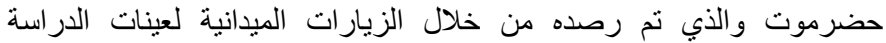

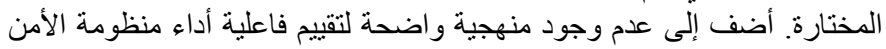

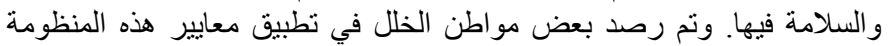

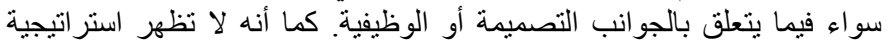

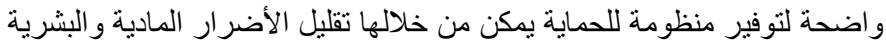

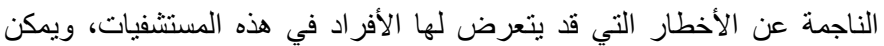

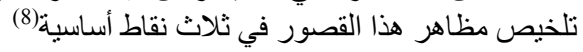

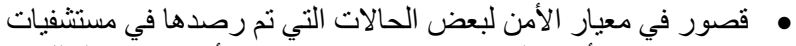

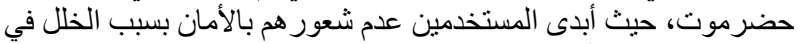
تطبيق المنظومة الأمنية، والتي تركزت التربن في نقاط التحكم في المداخل و المخارج الرئيسية وبعض مناطق الحنة الحركة في الأقسام الداخلية.

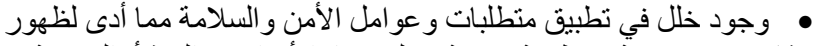

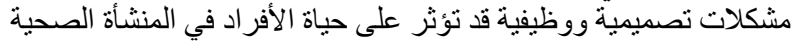

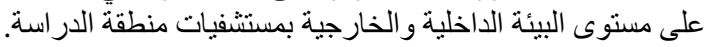

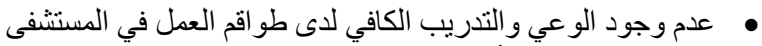

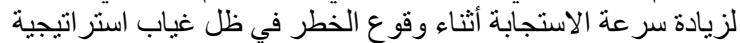
و اضحة للحماية من الأخطار المحتملة.

2-1 هدف البحث

تهدف الورقة البحثية من در اسة هذه الإشكالية إلى وضع تصور دقيق لمنهجية

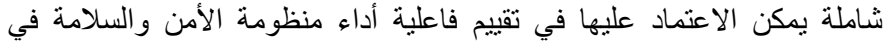
المستشفيات اليمنية وذلك من خلال تحقيق هدفين أساسيين : 


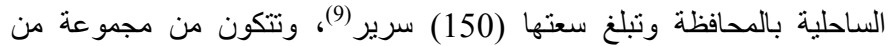

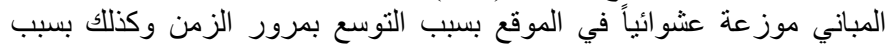
بناءها خلال فتر ات زمنية مختلفة.

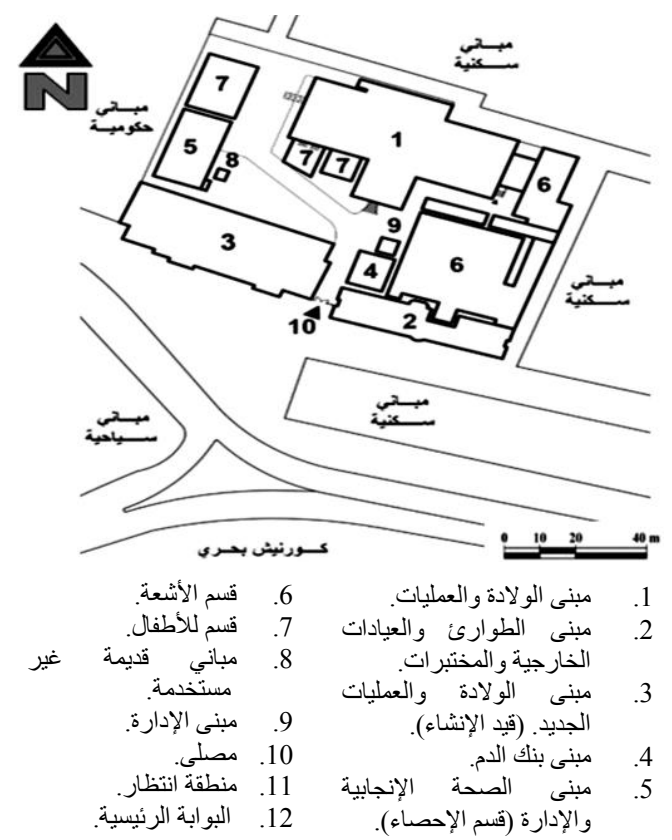

شكل (2): الموقع العام لمستشفى المكلا

2-1-3 مستشفى سيئون العام - مدينة سيئون

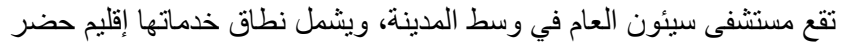

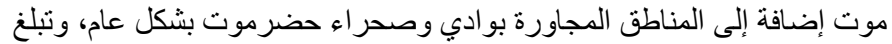

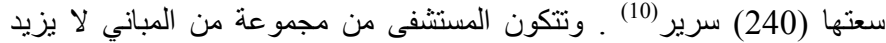
ارتفاعها عن دورين، ويلاحظ توزيع هذه المباني بشكل غير منتظم في الموقع بسبب بناء المستشفى عبر فتر ات زمنية مختلفة.

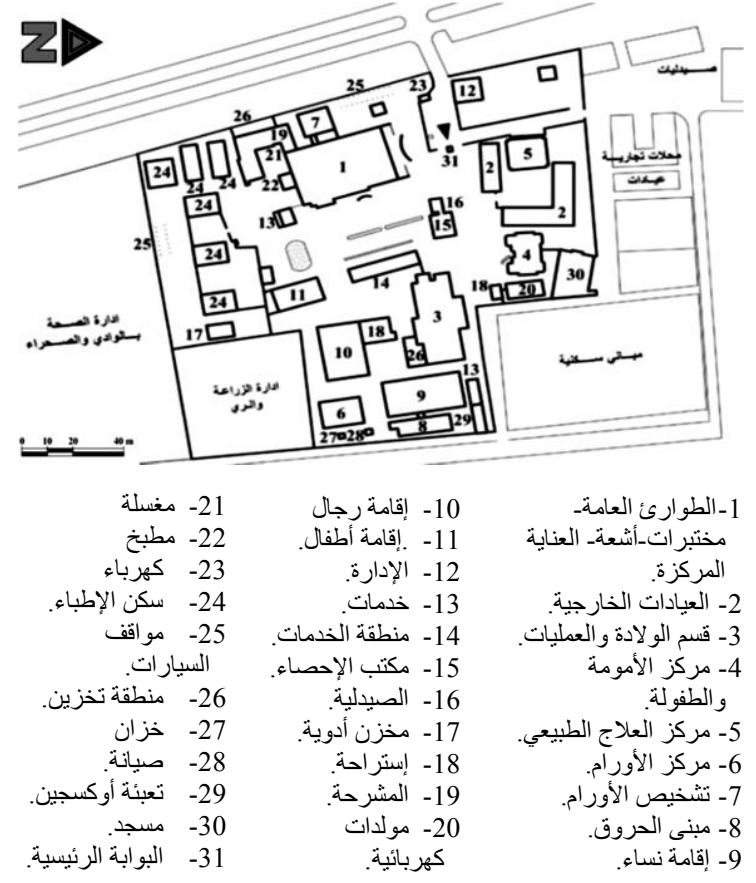

شكل (3): الموقع العام لمستثفى سيئون العام

$$
\text { 2-2 2 الدحور الثاني: تفعبل الدور الإداري }
$$

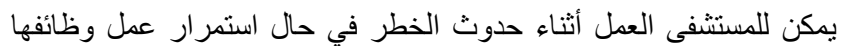

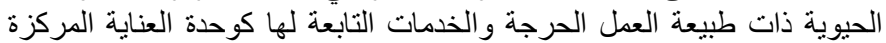

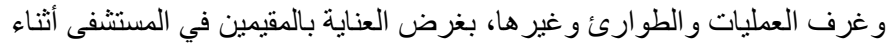

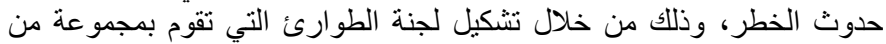
إجر اءات السلامة، ونشر الوعي، وندريب الموظفين للاستعداد للخطر و واستمر لفرار

تقديم الخدمات.

3-2 المحور الثالث: تحسبن القدرات

تحتاج إدارة المستشفيات أن تكون على دراية بالأخطار المتوقع الأن حدوثها

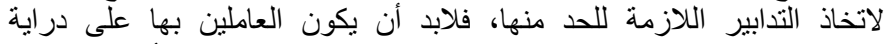

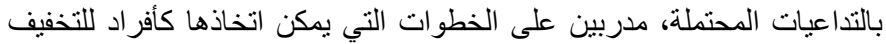

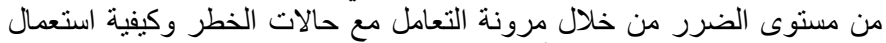

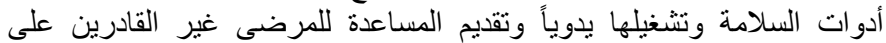
الحركة في حالة الإخلاء للتقليل من الخسائر المحتملة.

\section{تقييم فاعلية منظومة الأمن والسلامة في مباني المستشفيات اليمنية}

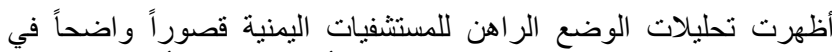

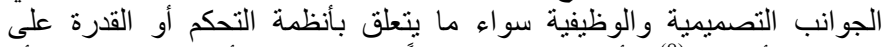

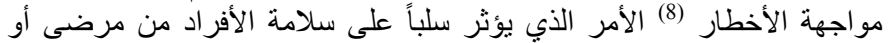

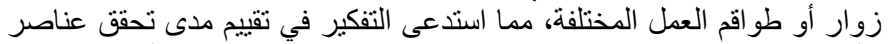

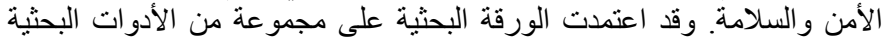

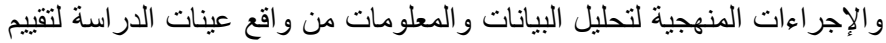

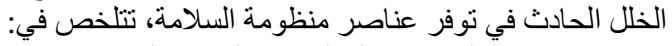

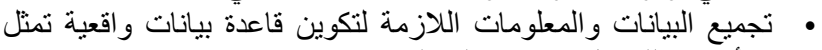
ركيزة أساسية للتعامل مع الإشكالية البحثية.

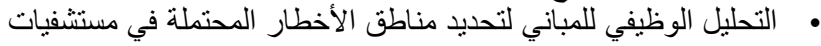
الحالات المختارة للار اسة البحثية. • الرصد الميداني و الملاحظات المباشرة من الفريق البحثي لو اقع مشكلات حالات الدراسة.

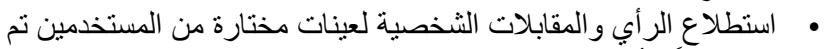

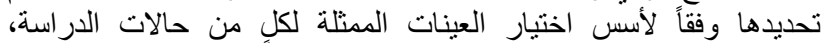

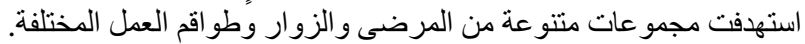

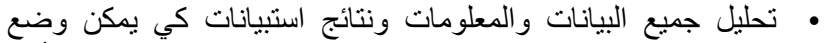

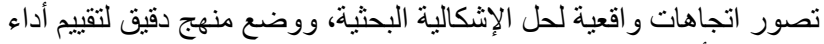
منظومة الأمن و السلامة. 1-3 تحديد حالات الدراسة كنماذج للتقبيم

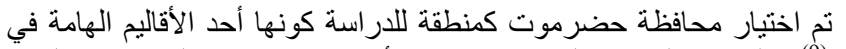

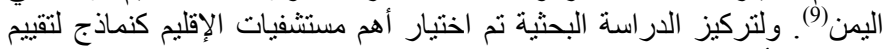

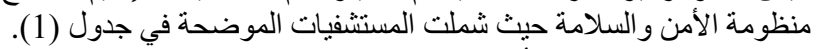

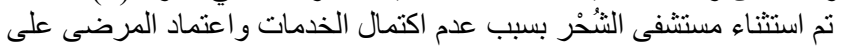

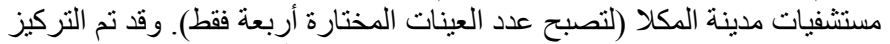

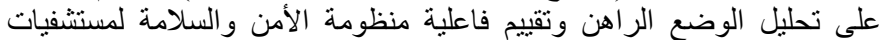

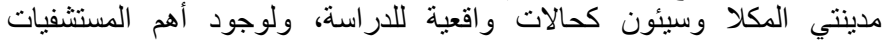
(1) و المنشآت الصحية فيها.

\begin{tabular}{|c|c|c|c|c|}
\hline الإداريم & المدينة & الأسرة & اسم المستثفى & s \\
\hline \multirow{3}{*}{ حضرموت } & \multirow[b]{2}{*}{ المكلا } & 300 & مستشفى ابن سيناء الجامعي & 1 \\
\hline & & 150 & مستشفى المكلا للأمومة & 2 \\
\hline & الثحر & 150 & مستشفى الثحر & 3 \\
\hline \multirow{2}{*}{ حضرموت } & سيئون & 214 & مستشفى سيئون العام & 4 \\
\hline & القطن & 116 & مستشفى القطن العام & 5 \\
\hline
\end{tabular}

1-1-3 مستشفى المكلا- مدينة المكلا

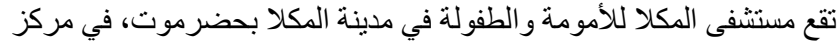
المدينة (المنطقة الوسطى) متعددة الوظائف. ويشمل نطاق خدماتها المنطقة 

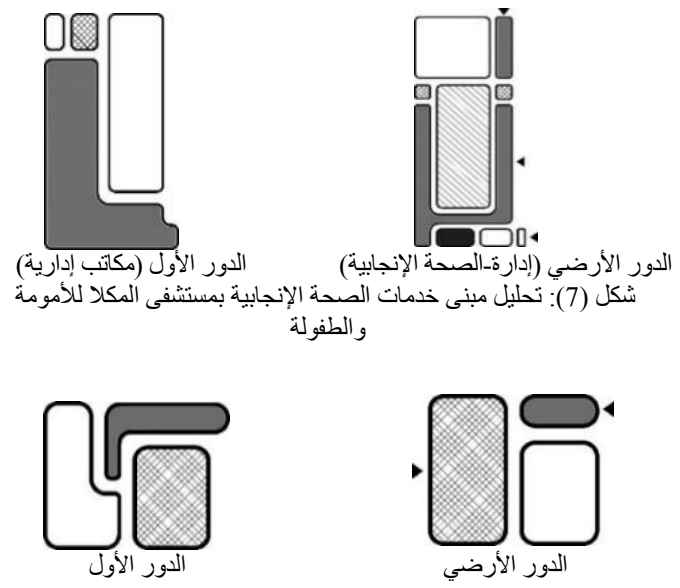

شكل (8): تحليل المسقط الأفقي لمبنى بنك الدم بمستشفى المكلا

2-2-3 تحلبل فاعلية منظومة الأمن والسلامة في مستشفى سيئون العام

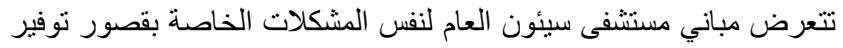

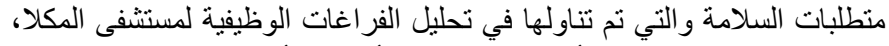

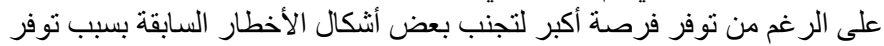
المساحة و إمكانية التوسع و السيطرة على فردل نقل العدوى بين الوظائف.

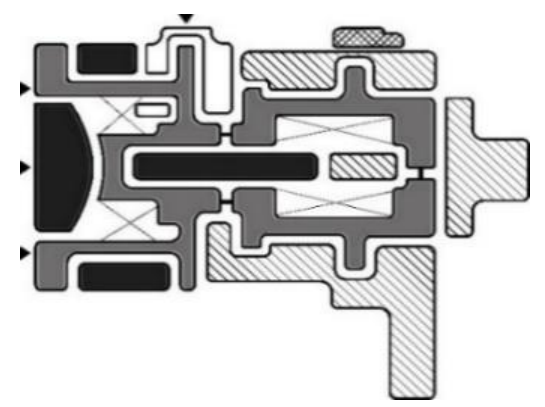

شكل (9): تحليل المسقط الأفقي لمبنى الطوارئ العامة بمستشفى سيئون العام.

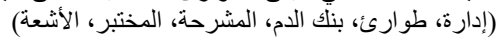

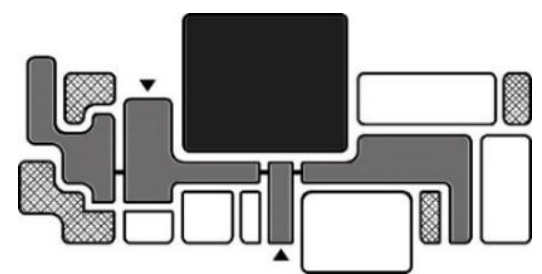

شكل (10): تحليل المسقط الأفقي لقسم الو لادة و العمليات بمستشفى سينون العام

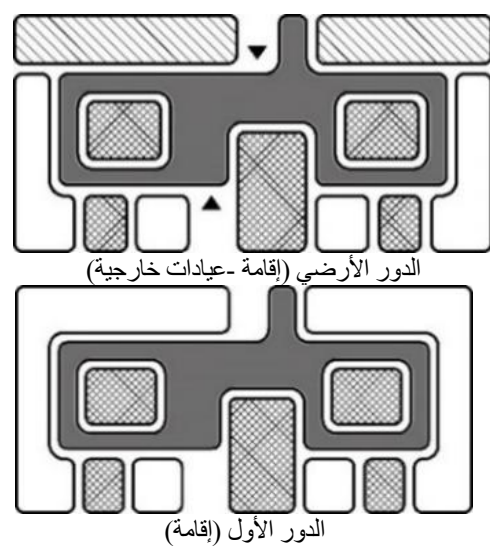

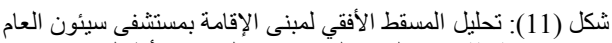
(ثلاثة مباني لنفس التصميم رجال ونساء أطفال)
2-3 تحليل فاعلبة منظومة الأمن والسلامة للفراغات الوظبفية بمستشفيات حضرموت

يتطلب تقييم فاعلية منظومة الأمن و السلامة تحليل الوضع الر اهن لمستشفيات

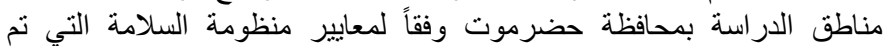

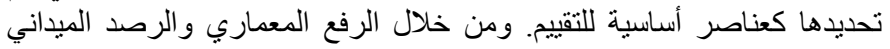

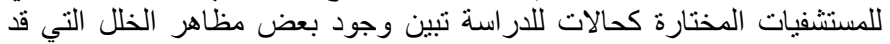

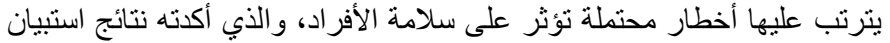

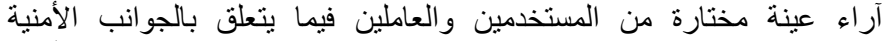

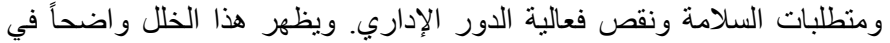

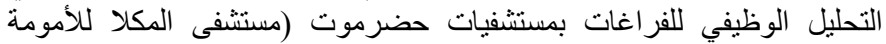

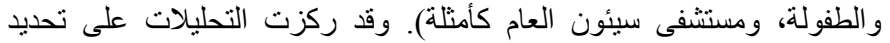

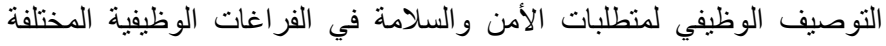
لمستشفيات حالات الدر اسة وتشمل:
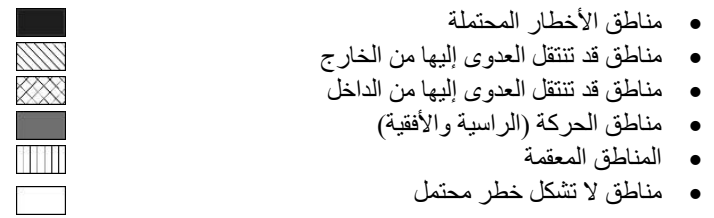

1-2-3 تحليل فاعلبة منظومة الأمن والسلامة في الفراغات الوظبفية في مستشفى المكلا

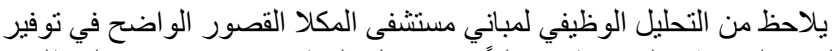

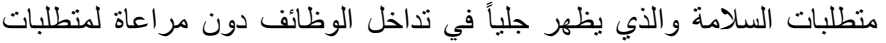

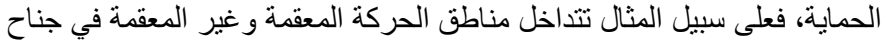

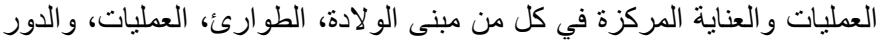

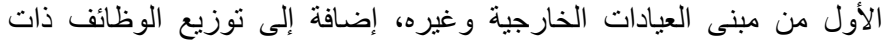

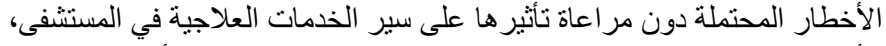
الأمر الذي يساعد على إمكانية نقل العدوى كما توضحه تحلير عليلات الأشكال التالية:
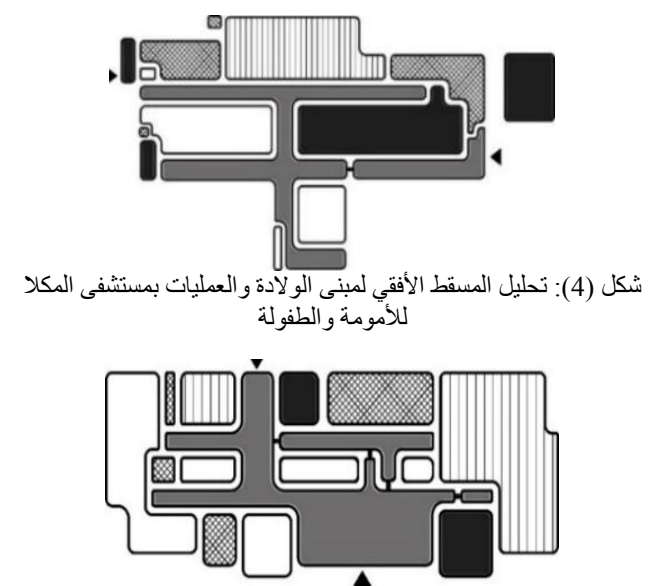
شكل (5): تحليل المسقط الأفقي للمبنى الطو ارئ وقسم العمليات بمستشفى المكلا

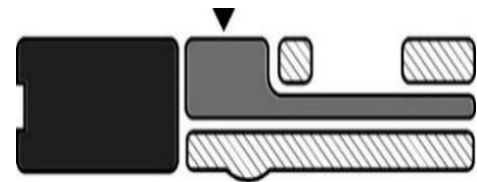

الدور الأرضي (العيادات الخارجية والطوارئ)

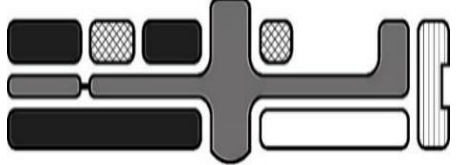

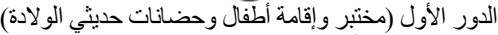

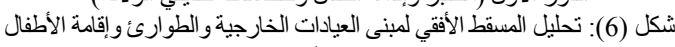
بمستشفى المكلا 
• معايير خاصة بالموقع العام للمستشفى والأخطار التي يمكن أن يتعرض التصن لهاو الخصائص الجيوتقنية للتربة. • • معايير إنشائية وتتركز على سلامة النظام الإنشائي وآثار الأخطار • • معايير غير إنشائية وتشمل المعايير التصميمية والتشغيلية التي تعمل التشل على استمر ار عمل الوظائف الحيوية.

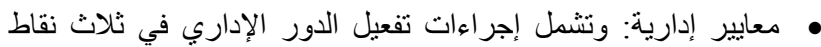

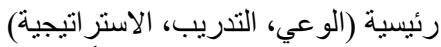

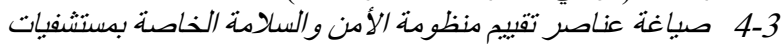

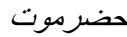

من خلال تحليل المنطلبات وتحديد أهم عناصر المنظومة الملائمة للبيئة

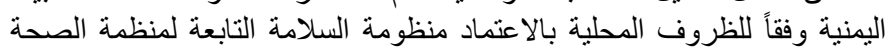

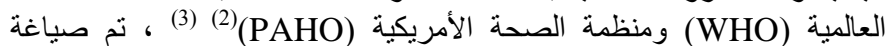

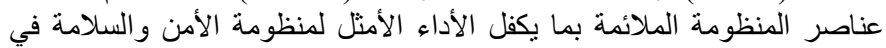

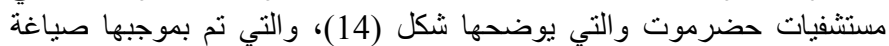
المنهجية الملائمة و التي تمثلت فيما يلي:

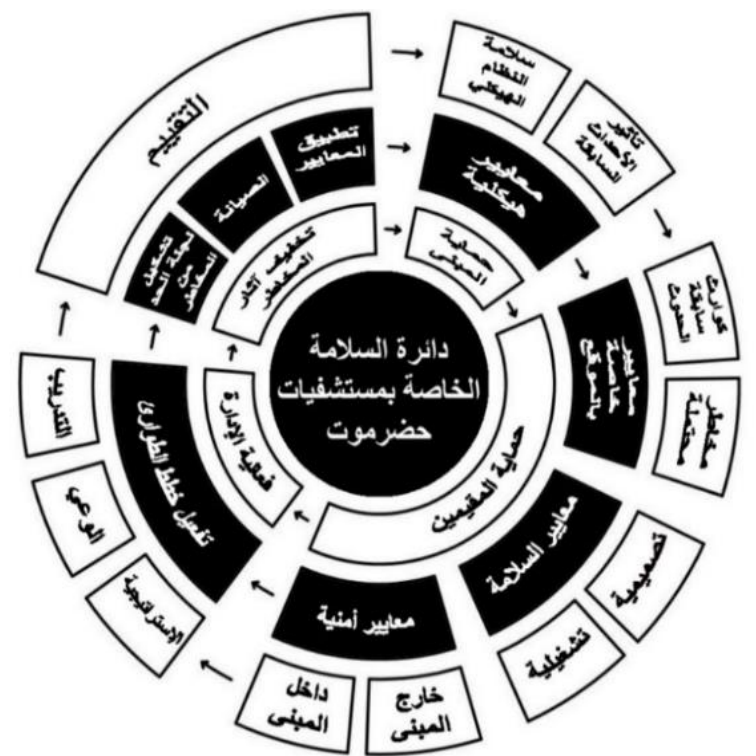

شكل (14): عناصر ومعايير تقييم منظومة الأمن و السلامة الخاصة بمسنشفيات حضرموت

• • إضافة المعيار الأمني كمعيار مهم لحماية الأفراد ــ لم يكن مدرجاً

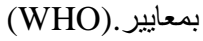

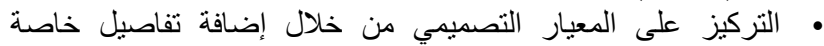
بالحماية من الأخطار الفنية والمنمثلة في الحماية من الحرائق، العدوى، التلوث، وأخطار الأشعة.

• تعديل التفاصيل الخاصة بحماية الأجهزة الطبية من الأخطار الطبيعية

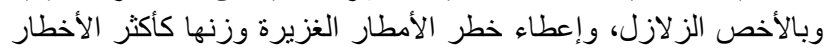
الطبيعية تأثيرًاً في منطقة الدار استة.

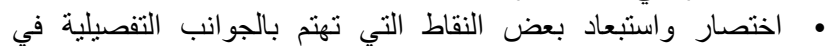
المعايير التشغيلية.

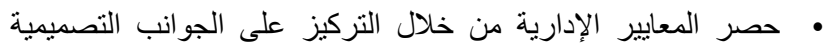

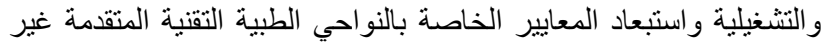

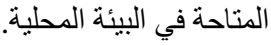

ت تحديد الأوزان النسبية الملائمة لعناصر منظومة الأمن والسلامة في اليمن . IV

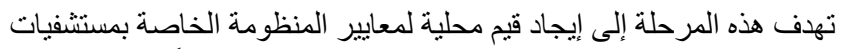

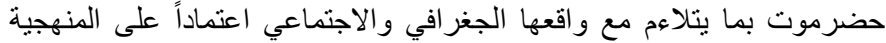

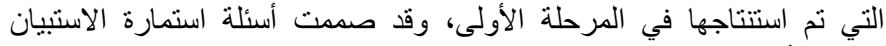
لاقتراح أوزان النسبية لمعايير تتو افق مع البيئة المحلية، للتعرف على آراء عينة الآني

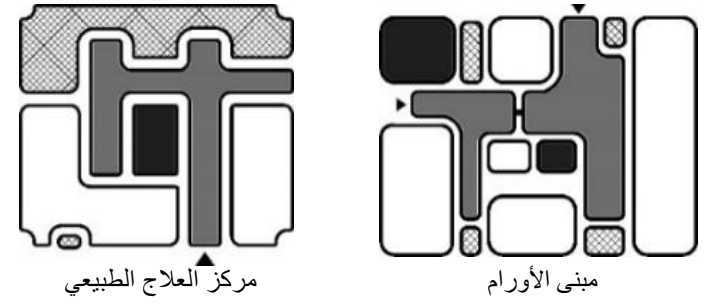

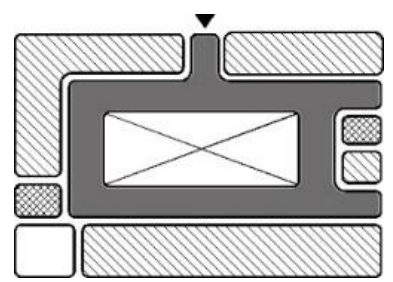

العيادات الخارجية الجديد

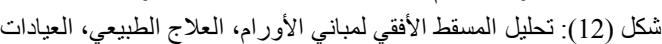
الخارجية بمسنشفى سيئون الاون

ليتبين من خلال التحليل الوظيفي لمنطلبات الأمن و السلامة بمستشفى سيئون

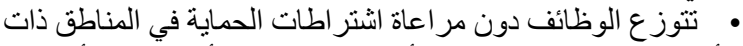

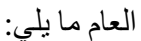

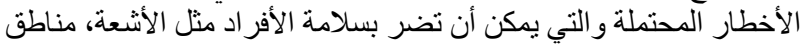
التلوث، مواد كيميائية و غير هاتيا. • علم مر اعاة فصل الوظائف الحيوية مثل العناية المركزة و العمليات عن

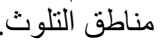
• • وجود خلل و اضح في توزيع الوظائف ذات العمل المتجانسة بما يعوق

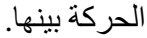
• • ساعد التداخل بين الوظائف على عدم القدرة على التحكم في مسارات

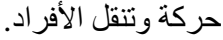

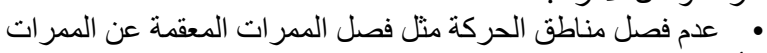

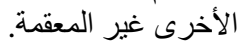

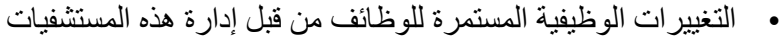

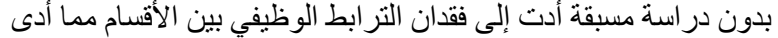
بدوره إلى نشوء مشكلات في انسجام وتناسق الأداء الوظيفي.

3-3 تحديد معايير تقيبيم منظومة الأمن والسلامة في مستثفيات حضرموت

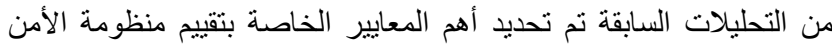

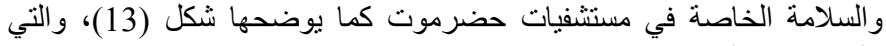
تنلخص فيما يلي:

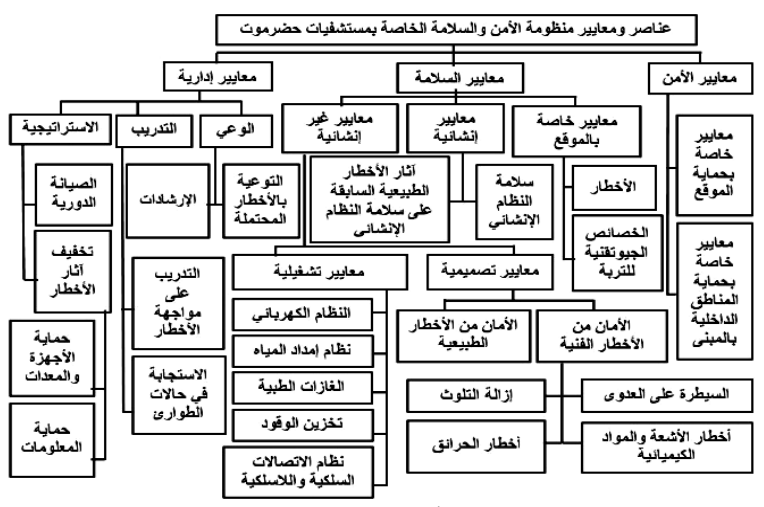

شكل (13): مكونات منظومة الأمن و السلامة الخاصة بمستشفيات حضرموت وللاحية

• • معايير أمنية: وتثمل المعايير الخاصة بالموقع العام للمستشفى والمعايير الخاصة بحماية محيطها الخارجي. معايير السلامة: تشمل ثلاث مكونات أساسية: 


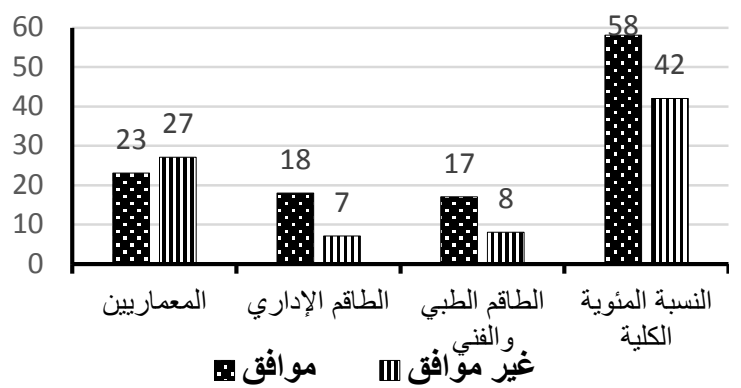

شكل (17): علاقة معيار السلامة غير الإنشائي (من الناحية التصميمية) بنتائج آراء الفئات الطبية و المتخصصين الانتين

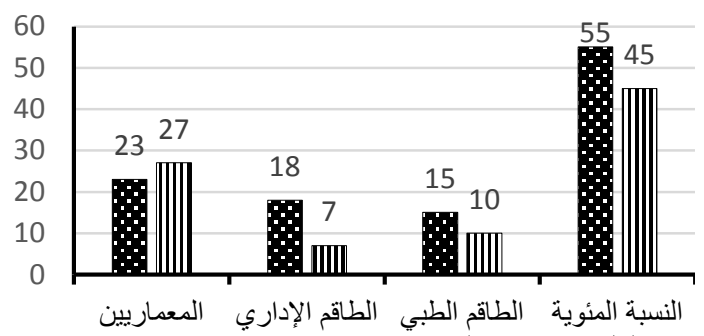

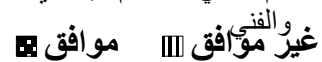

شكل (18): معيار السلامة غير الإنشائي (من الناحية التشغيلية) بنتائج آراء الفئات الطبية و المتخصصين (من النين

3-1-4 ت نتائج الأوزان المرجحة للمعبار الإداري تتكون نتائج المعيار الإداري من ثلاثة أقسام رئيسية وهي: (الاستر اتيجية، الوعي، التندريب).

1-2-1-4معيار الاستر/تيجية: تظهر النتائج متوسط الوزن النسبي (10\%) كبديل.

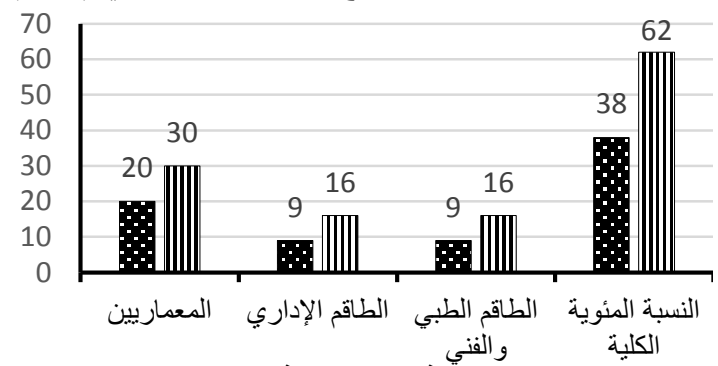

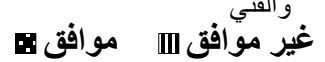

شكل (19): علاقة معيار الإدارة (الاستر اتيجية) بنتائج آراء الفئات الطبية و المتخصصين (الأنئن

2-2-1-4 معيار الوعي: تظهر النتائج اختيار متوسط الوزن النسبي (10\%) كبديل.

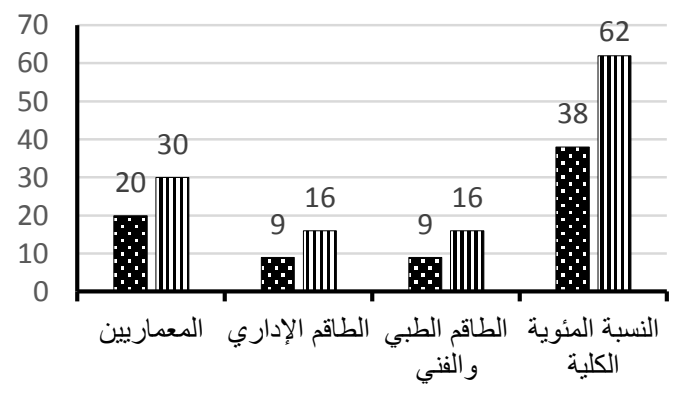

غير موافق موافي

شكل (20): علاقة معيار الإدارة (الوعي) بنتائج آراء الفئات الطبية

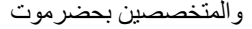

مختارة من الطو اقم الطبية والفنية والإدارية، وكذلك عينة مختارة من المعماريين،

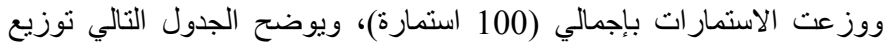
الاستمار ات على الفئات المختلفة:

جدول (2) تفصيل نوزيع استمار ات الاستبيان

\begin{tabular}{|c|c|c|c|}
\hline \multicolumn{3}{|c|}{ مستشفى المكلا للأمومة و الطفولة مدينة المكلا } & \multirow[b]{2}{*}{ بيان الاستمارات } \\
\hline الطتبيان الطاقم & استبيان الطاقم & المعماريين & \\
\hline \multicolumn{3}{|c|}{100} & إجمالي الاستمارات \\
\hline 25 & 25 & 50 & الاستمارات الموزعة \\
\hline 25 & 25 & 50 & الاستمارات المجمعة \\
\hline - & - & - & الاستمارات المفقودة \\
\hline
\end{tabular}

1-4 تحليل نتائج استبيان الرأي العينات الدختارة بنطقة الدراسة

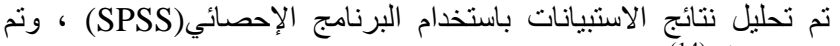

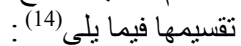

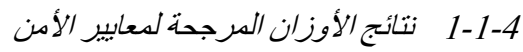
تظهر نتائج تحليل الاستيانات ترجيح متوسط الوزن النسبي بـ (10\%)

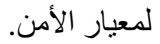
2-1-4 نتائج الأوزان المرجحة لدعايير السلامة تنقسم نتائج تحليل الاستبيانات إلى ثلاثة أقسام (معيار الموقع العام، معايير

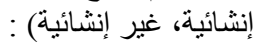

1-2-1-4 معيار الموقع العام للمستشفى: تظهر النتائج (ختيار منوسط (9) لوزئ) اللوزن النسبي الدحلي.

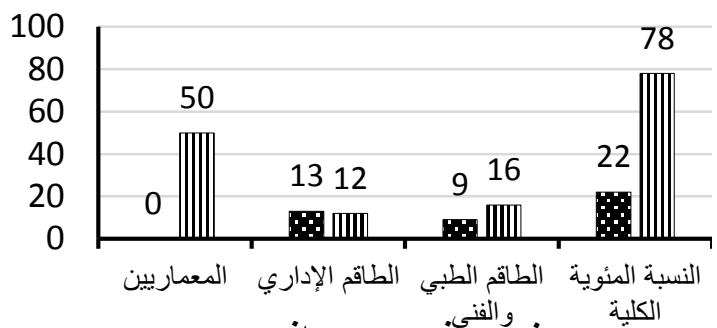

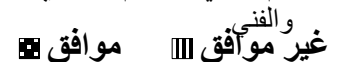

شكل (15): علاقة معيار الموقع العام للمستشفى بنتائج آراء الفئات الطبية

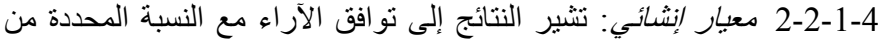

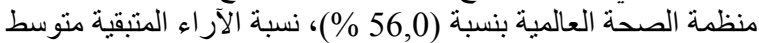
القيم (23\%) كبديل.

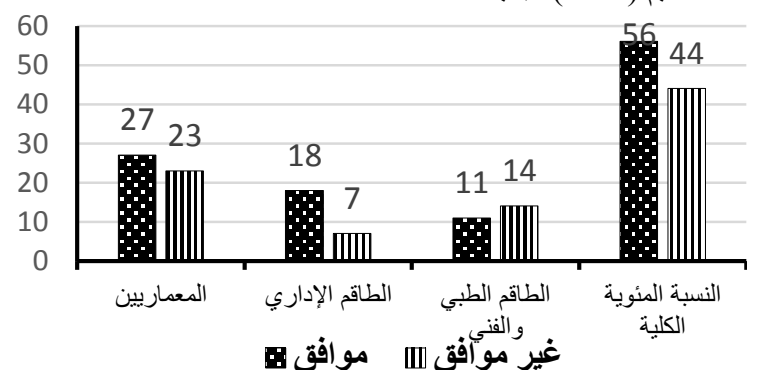

شكل (16): علاقة معيار السلامة الإنشائي بنتائج آراء الفئات الطبية و المتخصصين بحضرموت الإن

3-2-1-4 معابير غير إنشائية: تتقسم نتائج نحليل الاستيانات لهذا المعيار

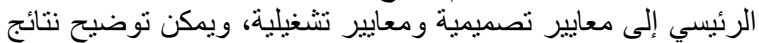
مكوناتها في الأشكال التالية. 
ومن خلال ما سبق من تحليل لاستبيانات الر أي يمكن استتباط الأوزان النسبية المقترحة لمعايير منظومة الأمن و السلامة الخاصة بمستشفيات حضرموت و التي

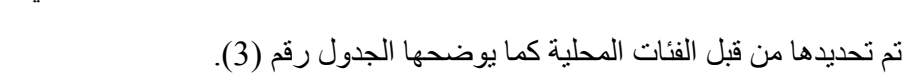
3-2-1-4 كبيلر التنريب: نظهر النتائج اختيار متوسط الوزن النسبي

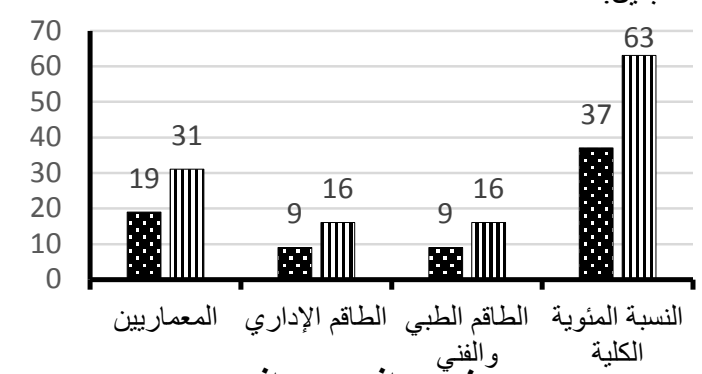

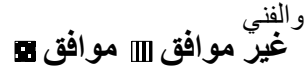

شكل (21): علاقة معيار الإدارة (التنريب) بنتائج آراء الفئات الطبية و المتخصصين

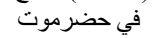

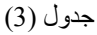

منوسط الأوزان النسبية المقترحة لمعايير منظومة السلامة من قبل الفئات الطبية والمتخصصين

\begin{tabular}{|c|c|c|c|c|c|c|c|c|c|}
\hline \multirow{3}{*}{\multicolumn{2}{|c|}{ بالمقياس المحلري }} & لعدم الموافقة النسب & موافق/ غير & قالصحمة & \multicolumn{5}{|c|}{ معايير الأمن والسلامة } \\
\hline & & \multirow{2}{*}{$\% 10$} & \multirow{2}{*}{ غير مو افق } & \multirow{2}{*}{$\% 0,0$} & حماية الموقع & \multirow{2}{*}{\multicolumn{3}{|c|}{ معايير الأمن }} & \multirow{2}{*}{1} \\
\hline & & & & & حماية داخلية & & & & \\
\hline \multirow{9}{*}{$\begin{array}{l}70 \\
\%\end{array}$} & \multirow{2}{*}{$\% 10$} & \multirow{2}{*}{$\% 9$} & \multirow{2}{*}{ غير مو افق } & \multirow{2}{*}{$\% 0,0$} & الحماية من الأخطار & \multirow{2}{*}{\multicolumn{2}{|c|}{ معايير خاصة }} & \multirow{9}{*}{ السلامةة } & \multirow{9}{*}{2} \\
\hline & & & & & الخصائص الجيوتقنية للتربة & & & & \\
\hline & \multirow{2}{*}{$\% 30$} & \multirow{2}{*}{$\% 23$} & \multirow{2}{*}{ 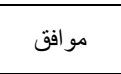 } & \multirow{2}{*}{$\% 50$} & سلامةٌ النظام الهيكلي & \multirow{2}{*}{\multicolumn{2}{|c|}{ معايير إنشائية }} & & \\
\hline & & & & & قلرة مقاومة الظواهر الطيعية & & & & \\
\hline & \multirow{2}{*}{$\% 15$} & \multirow{2}{*}{$\% 19$} & \multirow{2}{*}{ 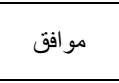 } & \multirow{5}{*}{$\% 30$} & الأمان من الأخطار الفنية & \multirow{2}{*}{ تصميمية } & \multirow{5}{*}{ 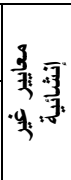 } & & \\
\hline & & & & & الأمان من الأخطار الطبيعية & & & & \\
\hline & \multirow{3}{*}{$\% 15$} & \multirow{3}{*}{$\% 18$} & \multirow{3}{*}{ 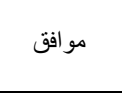 } & & أنظمة اتصالات & \multirow{3}{*}{ تثغيلية } & & & \\
\hline & & & & & أنظمة إمداد & & & & \\
\hline & & & & & أنظمة طبية & & & & \\
\hline \multirow{5}{*}{$\begin{array}{l}20 \\
\%\end{array}$} & \multirow{2}{*}{$\% 10$} & \multirow{2}{*}{$\% 10$} & \multirow{2}{*}{ غير موافق } & \multirow{5}{*}{$\% 20$} & النبيانة الدورية & تتراتيجية & & & \\
\hline & & & & & تخفيف آثار الأخطار & مح ايجية & & & \\
\hline & $\% 5$ & $\% 10$ & غير موافق & & الإرشيّة الأخطات العامة & 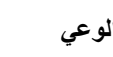 & & مهنية أو & 3 \\
\hline & & & & & التصريب على مواجهة الأخطار & & & & \\
\hline & $\% 5$ & $\% 9$ & غير مو افق & & سرعة الاستجابة حالة الطوارئ & تلتريب & & & \\
\hline & & & & $\% 100$ & & & $\varepsilon$ & & \\
\hline
\end{tabular}

و التي يتم بو اسطتها التوصل لتحديد مستوى الأمان لكل مستشفى بحسب تصنيف

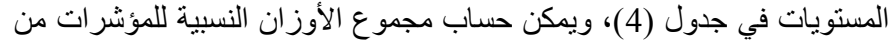

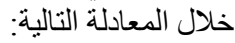

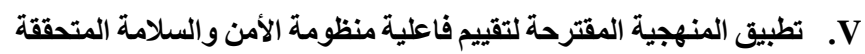

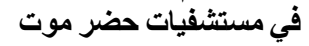

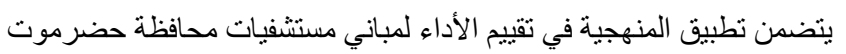

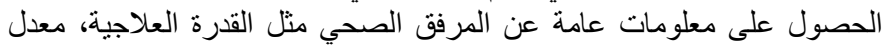
الإشغال و عدد الموظفين و غيره، وكذللك تحديد مستوى مؤشر ات ات الأمن و السلامة العلام

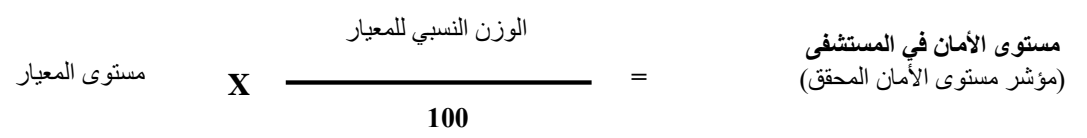

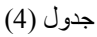

تصنيف مستويات تحقق معايير منظومة الأمن و السلامة الخاص بمستشفيات حضرموت

\begin{tabular}{|c|c|c|c|}
\hline البيان & مستوى الأمان & التصنيف & قيم مستوى الأمان \\
\hline 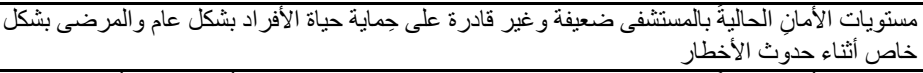 & منخفض & ج & $1-0$ \\
\hline الأخطار يات الأمانِ الحالية بالمستشفى تحتاج للتنخل بسبب احتمالية تعرّض حياة الأفر اد للخطر أثناء حدوث & متوسط & ب & $2-1<$ \\
\hline الأخطار مسات الأمانِ الحالية بالمسنشفى جيدة وقادرة على تحمل الأخطار وحماية حياة الأفر اد أثناء حدوث & عالي & أ & $3-2<$ \\
\hline
\end{tabular}




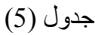

\begin{tabular}{|c|c|c|c|c|c|c|c|c|c|}
\hline \multicolumn{8}{|c|}{ مستوى الأمان } & \multirow{3}{*}{ اللمعاييزي } & \multirow{3}{*}{ 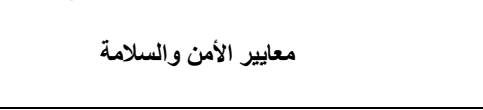 } \\
\hline \multirow{2}{*}{\multicolumn{2}{|c|}{ مستثفى(4) القطن العام }} & \multirow{2}{*}{\multicolumn{2}{|c|}{ سيئون العام }} & \multirow{2}{*}{\multicolumn{2}{|c|}{ مستثفى(2) ميناء }} & \multirow{2}{*}{\multicolumn{2}{|c|}{ مستشفى(1) }} & & \\
\hline & & & & & & & & & \\
\hline \multirow[t]{2}{*}{ 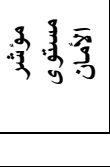 } & \multirow[t]{2}{*}{ ज़ु } & 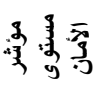 & 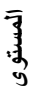 & 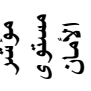 & बु & 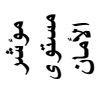 & जु & $\% 10$ & 1- المعايير الأمنية \\
\hline & & & & & & & & $\% 4$ & 1-1-1 نطاق الحماية الخارجي \\
\hline 0,04 & 2 & 0,04 & 2 & 0,02 & 1 & 0,02 & 1 & $\% 2$ & 1-1-2-1- حماية محيطموقع المستشفى \\
\hline 0,02 & 1 & 0,02 & 1 & 0,04 & 2 & 0,02 & 1 & $\% 2$ & |-2-2-1- حماية محيط مبنى المستشفى \\
\hline \multirow[t]{2}{*}{0,06} & - & 0,06 & - & 0,06 & - & 0,04 & & & المجموع الفرعي (1) \\
\hline & & & & & & & & $\% 6$ & -1 2-1 - نطاق الحماية الداخلي \\
\hline 0,02 & 1 & 0,02 & 1 & 0,04 & 2 & 0,02 & 1 & $\% 2$ & -3-2-1- حماية الوظائف الحيوية وفصلها عن الزوَار \\
\hline 0,04 & 2 & 0,04 & 2 & 0,04 & 2 & 0,04 & 2 & $\% 2$ & 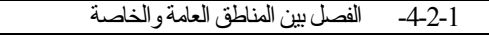 \\
\hline 0,02 & 1 & 0,02 & 1 & 0,02 & 1 & 0,02 & 1 & $\% 2$ & 1-5-2-1- حماية المناطق المعرّضة للسرقة \\
\hline 0,08 & & 0,08 & & 0,1 & & 0,08 & & & المجموع الفرعي (2) \\
\hline 0,14 & & 0,14 & & $\mathbf{0 , 1 6}$ & & 0,12 & & & المجموع الكلي لمعيار الأمن \\
\hline
\end{tabular}

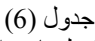

النتائج الإجمالية لتحديد مستويات الأمان لمعايير الأمن و السلامة بمستشفيات حضرموت

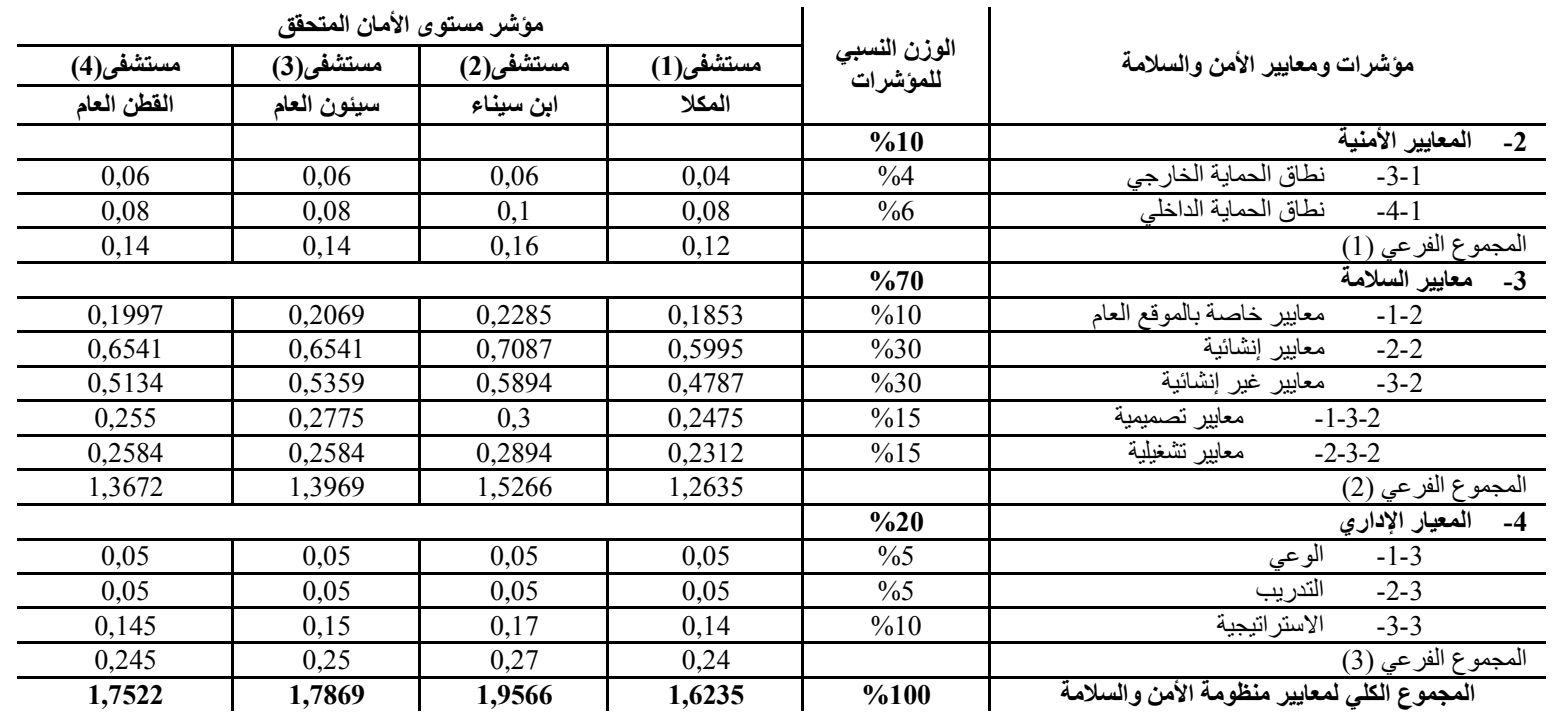

وهو بذلك يثير إلى ضعف تحقق مستويات الأمان وضرورة التدخل لمعالجة

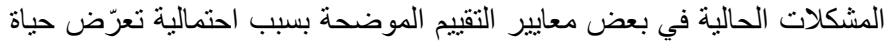
الأفر اد فيها للخطر أثناء حدوث الحُ الأخطار .

\section{VII}

من خلال المنهجية المقترحة والتي تم إتباعها في عملية تقييم فاعلية منظومة

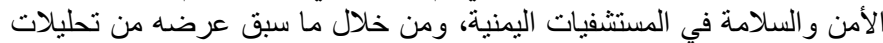

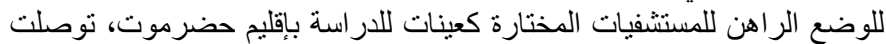

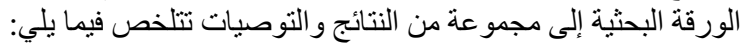

1-7 النتائج

بناءً على ما سبق تتلخص نتائج التحليلات والدراسات التي تناولتها الورقة

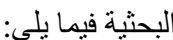

• تبين من استبيان آراء عينات الدراسة المختارة أن هنالك مجموعة من فئل

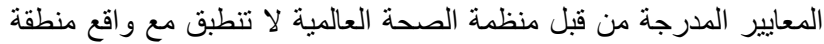

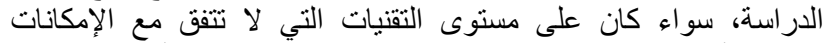

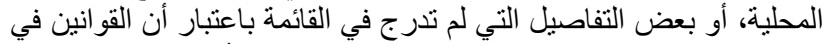

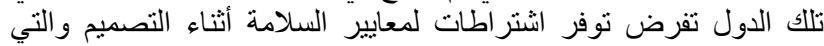
يختلف فيها الوضع في اليمن حيث يتم فرض الاشتر اطات دون مرانئ اقبة من الجهات المسئولة.
فعلى سبيل المثال يتكون المعيار الأمني من قسمين رئيسيين: نطاق حماية

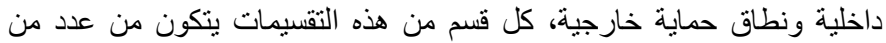

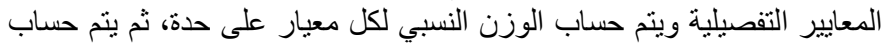

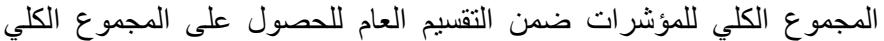

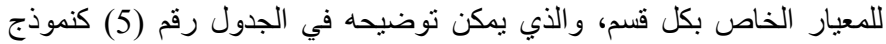
تفصيلي لكيفية حساب مستويات الأمان المحققة. ويوضح جدول رقم (6) ملخص نتائج الحسابات الخاصة بتقييم معايير

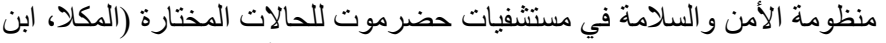

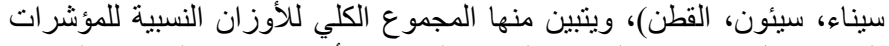

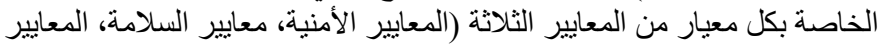

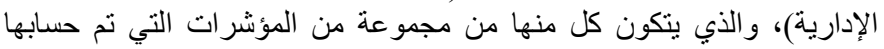

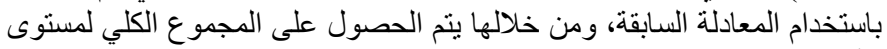
الأمان للمعايير الموضحة في الجدول.

\section{|VI}

يتضح مما سبق عرضه من نتائج التحليلات وبيانات تقييم فاعلية أداء منظومة

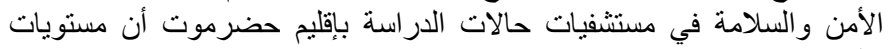

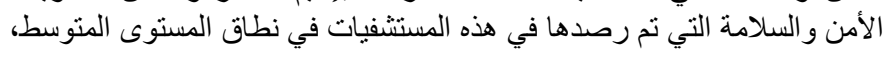


• وضع خطط و استر اتيجيات على المدى البعيد للعمل على تفعيل الاعتماد

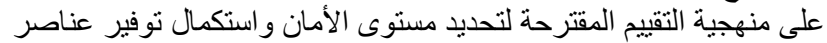

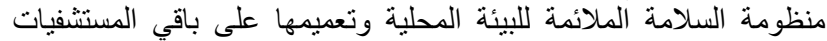

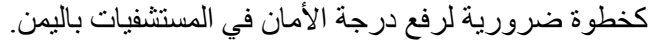

\section{المراجع والهوامش}

[1] World Health Organization (WHO), 2009: "Regional Health Forum", the WHO Regional Office for South- East Asia, New Delhi, India.

[2] World Health Organization (WHO), \& Pan American Health Organization (PAHO), 2008: "Hospital Safety Index Evaluation Forms for Safe Hospitals", Washington DCC Pan American Health, USA.

[3] Department of Health-Health Emergency Management Staff (DOHHEMS) and National Center for Health Facility Development (DOHNCHFD), 2008: "Hospitals Should be Safe from Disasters", with support from the Association of Hospital Administrators and the World Health Organization - Western Pacific Regional Office (WHO-WPRO).

[4] The Association of Chief Police Officers, 2005: "Secured by Design Hospitals", London.

[5] International Association Healthcare for Security \& Safety, 2012: "Security Design Guidelines for Healthcare Facilities", the 2012 edition of the Security Design Guidelines for Healthcare Facilities was developed by the IAHSS Guidelines Council and funded by the International Healthcare Security \& Safety Foundation, Glendale Heights, USA.

[6] World Health Organization (WHO) \& Pan American Health Organization (PAHO, 2003: "Protecting new health facilities from natural hazards: guidelines for the promotion of disaster mitigation", based on Guidelines for Vulnerability Reduction in the Design of New Health, University of Chile, El Salvador.

[7] Medical Devices Management Group, Risk Management Committee, 2010: "Medical Equipment Policy v3.0", England.

[8] وفاء عبداله بلعلا، خالد محمد أحمد الليثي، 2015:"تحليل احتياجات الأمن و السلامة في تصميم

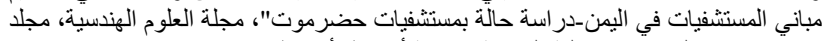

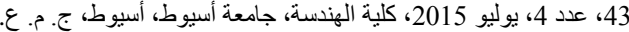

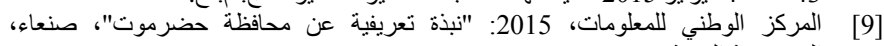

http://www.yemen-nic.info/gover/hathramoot/brife

[10] وزارة الصحة العامة و السكان: "التقرير الإحصائي السنوي لعام2008م "، صنعاء، الجمهورية

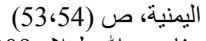

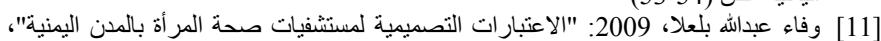

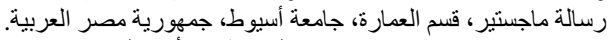

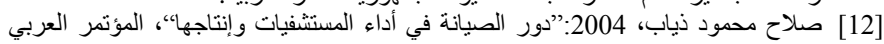

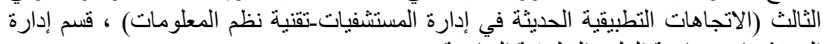

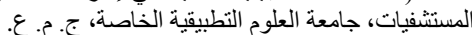

[13] الدالة المعنوية الإحصائية هي قيمة احتمالية تعبر عن من مستوى الخطأ المحتمل، ولها ثلاثة

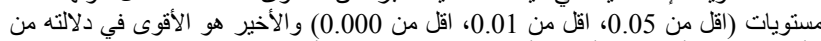

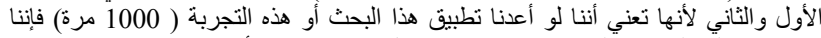

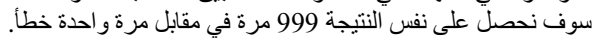

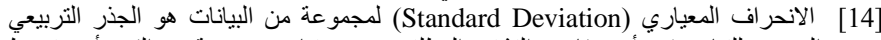

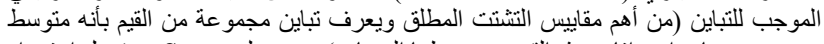

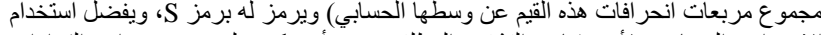
الانحراف المعياري لأن مقياس التشتت المطلق يجب أن يكون له نفس وحدات القراءات
• إضافة معيار الأمن لزيادة إحساس المستخدمين بالأمان في المرفق المانق

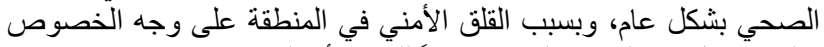
و الذي يجعل من المباني الصحية هدفاً للسرقة أو التخري التخريب.

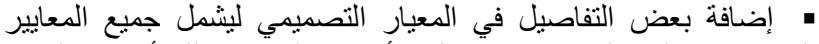

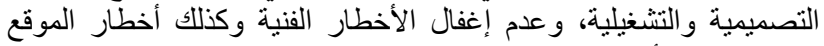

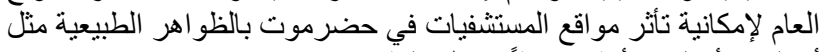
أخطار الأمطار الأكثر حدوثاً في المنطقة.

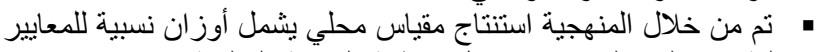

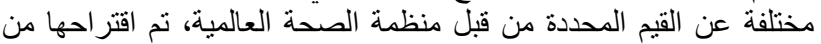
واقع ظروف المنطقة البحثية للتوصل إلى أرقام منطقية لمستويات الأمان.

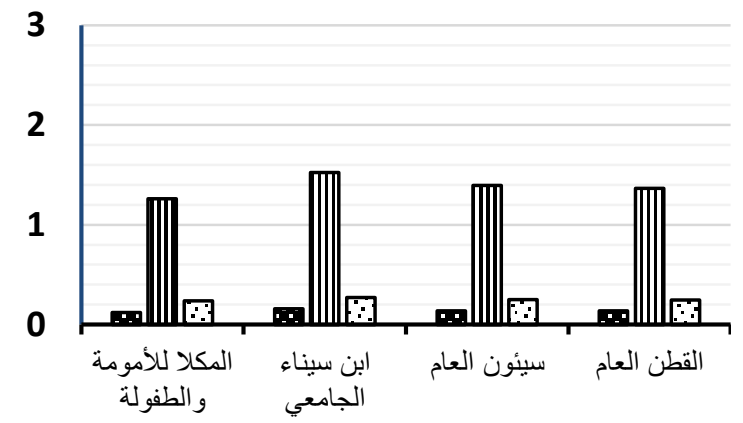

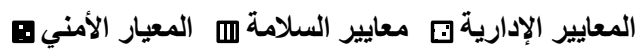

شكل (22): مستويات معايير الأمان لمنظومة الأمن و السلامة في مستثفيات حضرموت

• من خلال تحليلات قيم مستوى الأمان المحققة لعينات الدراسة

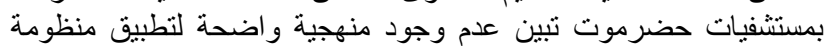

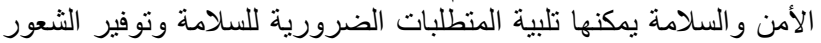
بالأمان لدى المستخدمين وطو اقم العمل. 2-7 التوصيات

بناءً على النتائج التي تم عرضها توصلت الورقة البحثية إلى مجموعة من الوناء

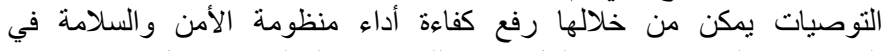

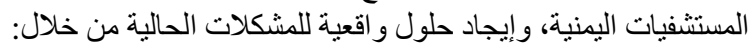

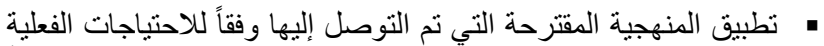

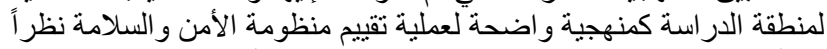

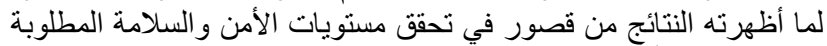

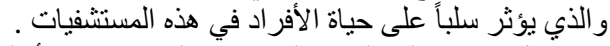

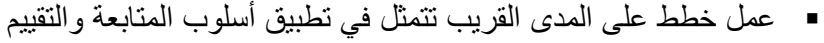

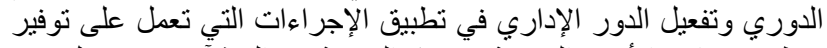

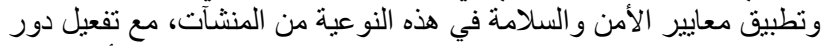
المراقبة واستشارة المتخصصين سواء في في مرحلة التصميم أو أو إجراء

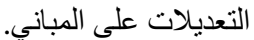

